OSAHS

\title{
Moderate OSAS and turbinate decongestion: surgical efficacy in improving the quality of life and compliance of CPAP using Epworth score and SNOT-20 score
}

\author{
OSAS di grado moderato e decongestione dei turbinati: \\ efficacia chirurgica nel migliorare la qualità di vita e la compliance della CPAP \\ utilizzando l'Epworth score e lo SNOT-20 score
}

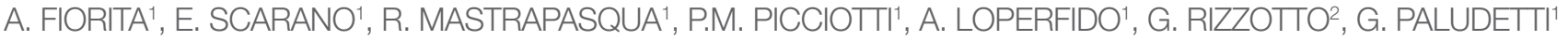 \\ ${ }^{1}$ Department of Head and Neck Surgery, Otorhinolaryngology, ${ }^{2}$ Department of Neuroscience, Catholic University of \\ Sacred Heart, Rome, Italy
}

\section{SUMMARY}

Drug-induced sleep endoscopy (DISE) is an important procedure in diagnostic pathway of patients affected by moderate OSAS. However, the Italian National Health System does not provide any compatible Diagnosis-related-group (DRG) code codification for DISE, which makes it impossible to obtain regional reimbursement. In order to overcome this problem, DISE is usually associated with other codified surgical procedures. The aim of our study is to assess the association of turbinate decongestion (TD) and DISE in order to combine in a single operating session diagnostic and therapeutic procedures. The objective of our work is to assess the role of nasal surgery on symptoms of moderate OSA. Recent studies have confirmed that isolated nasal surgery improves quality of life (QOL), but not the apnoea hypopnoea index (AHI) during polygraph registration. We enrolled 30 patients, aged between 29 and 64 years (mean $50.53 \pm 9.20$ ), 26 males and 4 females, with a mean BMI of $26.07 \pm 2.81 \mathrm{~kg} / \mathrm{m}^{2}$, who were affected by moderate OSAS. All patients underwent otolaryngologycal pre-operative evaluation, home respiratory polygraph and subjective evaluation through Sino-Nasal-Outcome Test (SNOT-20) and Epworth Sleepiness Scale (ESS). During the same surgery session, they underwent DISE and TD. Patients were re-evaluated six months later using the same questionnaires. We observed a significant improvement ( $<<0.05)$ in both the mean ESS index $(6.03 \pm 2.75$ vs $4.16 \pm 4.63)$ and total SNOT score $(22.53 \pm 12.16$ vs $13.23 \pm 10.82)$. Significant differences $(p<0.05)$ were also identified for partial SNOT questions $1-11(9.1 \pm 5.11$ vs $6.13 \pm 4.12)$ and $11-20(13.36 \pm 10.20$ vs $7.13 \pm 9.644)$. The results of the present study confirm that TD alone can improve sleepiness, QOL and nasal symptoms. Thus, in absence of a National Health System recognition for DISE, the association of this procedure with TD can be useful for diagnostic and therapeutic management of OSAS, improving CPAP compliance and adherence, reducing sleepiness, ameliorating nasal symptoms and therefore QOL.

KEY WORDS: DISE (Drug Induced Sleep Endoscopy) • OSAS (Obstructive Sleep Apnoea Syndrome) • Epworth score• SNOT-20 score • QOL (Quality of Life)

\begin{abstract}
RIASSUNTO
La DISE (Drug Induced Sleep Endoscopy) è una procedura importante nella gestione diagnostica dei pazienti affetti da OSAS moderata. Il Sistema Sanitario Nazionale, tuttavia, non riconosce alcun DRG per tale metodica e ciò non consente di ottenere il rimborso regionale. Per superare questo problema di gestione di spesa sanitaria, di solito si associa la DISE a un'altra procedura chirurgica codificata. L'obiettivo del nostro studio è definire se l'associazione della decongestione dei turbinati alla DISE possa garantire un risultato terapeutico in aggiunta alla procedura diagnostica e migliorare la sintomatologia dei pazienti affetti da OSAS moderata. Recenti studi confermano che la sola chirurgia nasale migliora la qualità di vita ma non l'AHI (Indice Apnea-Ipopnea) durante la polisonnografia. Abbiamo arruolato 30 pazienti di età compresa tra 29 e 64 anni (media 50,53 \pm 9,20), 26 maschi e 4 femmine con un BMI medio di 26,07 $\pm 2,81 \mathrm{~kg} / \mathrm{m}^{2}$. Tutti i pazienti sono stati sottoposti a valutazione obiettiva ORL pre-operatoria, registrazione polisonnografica domiciliare e ai questionari SNOT-20 e scala della sonnolenza di Epworth. Durante la stessa sessione chirurgica i pazienti sono stati sottoposti a DISE e in seguito a decongestione dei turbinati inferiori. I pazienti sono stati rivalutati a sei mesi tramite i medesimi questionari. Abbiamo osservato un miglioramento significativo $(p<0,05)$ sia nella media dei punteggi del questionario di Epworth $(6,03 \pm 2,75$ vs 4,16 4 4,63) sia nel punteggio totale dello SNOT-20 (22,53 $\pm 12,16$ vs 13,23 $\pm 10,82)$. Sono state riscontrate differenze significative $(p<0,05)$ anche nei punteggi parziali delle domande 1-11 dello SNOT-20 $(9,1 \pm 5,11$ vs 6,13 \pm 4,12) e 11-20 (13,36 \pm 10,20 vs $7,13 \pm 9,644)$. I risultati del nostro studio confermano che la decongestione dei turbinati può migliorare sia la sonnolenza che la qualità di vita ed i sintomi ostruttivi nasali. Ciononostante, nell'assenza di un riconoscimento da parte del Sistema Sanitario Nazionale per la procedura DISE, l'associazione tra questa indagine e la decongestione dei turbinati può essere utile per l'iter diagnostico-terapeutico del paziente OSAS, migliorando la compliance verso la CPAP e la qualità di vita, nel contempo riducendo la sonnolenza e i sintomi ostruttivi respiratori nasali.
\end{abstract}

PAROLE CHIAVE: DISE (Drug Induced Sleep Endoscopy) • OSAS (Obstructive Sleep Apnoea Syndrome) • Epworth score • SNOT-20 score $\bullet$ QOL (Qualità di Vita)

Acta Otorhinolaryngol Ital 2018;38:214-221 


\section{Introduction}

Sleep-disordered breathing and obstructive sleep apnoea syndrome (OSAS) are common and increasingly important conditions in modern society. OSAS can influence general health status, occupational and family management. It can affect both cardiovascular and neurological systems. OSAS arises from obstruction of the upper airway during sleep at multiple levels, such as nasal cavity, pharyngeal cavity, and retroglottic and glottis regions. Among these, the nasal cavity accounts for $1 / 2$ to $2 / 3$ of general airway resistance. Nasal obstruction can result from multiple causes, including mucosal inflammation and structural abnormalities, such as septal deviation, nasal valve compromise and turbinate hypertrophy. The prevalence of OSAS is estimated to range from $3.1 \%$ to $7.5 \%$ in the adult male population. Diagnosis of OSA usually requires overnight polysomnography (PSG) to detect the frequency of apneic and hypopnoeic events. Continuous positive airway pressure (CPAP) is currently considered the gold standard for treatment of OSA.

Drug-induced sleep/sedation endoscopy (DISE), first described by Croft and Pringle in $1991^{1}$, enables exploration of upper airways during induced sleep. It is relatively quick and simple, targeting possible obstruction sites. A recent review by Blumen et al. ${ }^{23}$ discusses the role of DISE as gold standard in diagnosis of OSAS, but this role is not yet well codified.

However, although DISE certainly has an important role in the diagnostic pathway of patients affected by moderate OSAS ${ }^{4}$, at present the Italian National Health System does not provide any compatible Diagnosis-RelatedGroup (DRG) code codification. In order to overcome this economic and organisational problem, DISE can be associated can be associated with well codified surgical nasal procedures and refunded by the Regions.

Regarding the role of nasal surgery in OSAS, a recent meta-analysis by $\mathrm{Wu}$ et al. ${ }^{5}$ pointed out that surgery on the nose can significantly improve the quality of life in patients affected by OSAS, especially those with nasal obstruction. The authors concluded that both apnea-hypopnea index (AHI) and Epworth Sleepiness Scale (ESS) (Fig. 1) significantly improve after isolated nasal surgery, but the improvement of AHI is slightly significant.

Moreover, other studies have evaluated the effect of nasal surgery on CPAP. Camacho et al. ${ }^{6}$ conducted a systematic review and meta-analysis evaluating the effects of isolated nasal surgery on therapeutic CPAP device pressures and use in adults with OSA. The authors demonstrated that isolated nasal surgery in patients with OSAS with nasal obstruction reduces therapeutic CPAP device pressures and also increases use of.CPAP in selected patients. Ishii et al also investigated if nasal surgery can improve OSAS in patients with nasal obstruction and OSAS. They showed that isolated nasal surgery in these patients led to significant improvements in ESS and Respiratory Disturbance Index (RDI), but no significant improvements in AHI. One bias of these reviews and related papers is related to the absence of a specific analysis of the different nasal surgical approaches, and especially for turbinate decongestion.

It has been demonstrated by Powell et al. ${ }^{8}$ that nasal surgery synergises the effects of CPAP treatment, but the majority of studies that involve the nasal district focus on nose surgery, combining various approaches without separately analysing the impact of septal surgery and turbinate decongestion ${ }^{9}$.

Finally, regarding costs, Kempfle et al. ${ }^{10}$ evaluated the cost-effectiveness of two types of nasal surgery versus no surgery in patients with OSA and nasal obstruction undergoing CPAP. The authors followed the contributor citizen viewpoint, comparing the cost of untreated OSAS patients, cost and complications of surgery and annual cost of CPAP. They concluded that the cost-effectiveness of nasal surgery is in improving CPAP compliance in the OSAS population with nasal obstruction, indicating the value of surgical intervention for non-adherent CPAP users or partially adherent users, as part of a multifaceted approach to improving overall compliance.

We currently associate turbinate decongestion with DISE, considering that the nasal cavities can affect the pathophysiology of OSAS in multiple ways ${ }^{11}$ providing a stable airway while oral cavity and larynx collapse ${ }^{12}$.

On the basis of these scientific studies of the literature and Italian and non-Italian economic considerations, the aim of this study is to assess the benefits of associating TD and DISE in ameliorating the diagnostic and therapeutic tools of OSAS, and in improving quality of life (QOL), sleepiness and nasal symptoms.

\section{Materials and methods}

Weenrolled 30 patients, aged between 29 and 64 years (mean $50.53 \pm 9.20), 26$ males and 4 females, with a mean BMI of $26.07 \pm 2.81 \mathrm{~kg} / \mathrm{m}^{2}$, admitted to the Department of Head and Neck Surgery "A. Gemelli Hospital" Catholic University School of Medicine and Surgery in Rome. Patients were affected by moderate OSAS $15<\mathrm{AHI}<30$ events/h (mean AHI 21.04 events/h DS: \pm 4.79 considering a $3 \%$ dip of saturation) diagnosed with polysomnography. They underwent DISE and turbinate decongestion during the same session. The study was approved by the Ethics Com- 


\section{Epworth Sleepiness Scale}

Use this scale to determine your patient's level of sleepiness.

$$
\begin{aligned}
& \text { Choose the most appropriate number for each situation: } \\
& \qquad \begin{aligned}
0 & =\text { no chance of dozing } \\
1 & =\text { slight chance of dozing or sleeping } \\
2 & =\text { moderate chance of dozing or sleeping } \\
3 & =\text { high chance of dozing or sleeping }
\end{aligned}
\end{aligned}
$$

Situation
Sitting and reading
Watching TV
Sitting inactive in a public place
As a passenger in a motor vehicle for an hour or more
Lying down to rest in the afternoon when circumstances permits
Sitting and talking to someone
Sitting quickly after lunch without alcohol
In a car, while stopped for a few minutes in traffic
Total score (add the scores up)
(This is your Epworth score)

If your patient scores 10 or more, we recommend your patient consult one of our physicians to treat a sleep disorder, address an underlying condition affecting sleep and develop proper sleep hygiene.

Fig. 1. Epworth Sleepiness Scale (Vignatelli L, et al., $2003^{7}$ ).

mittee of the Catholic University School of Medicine and Surgery in Rome. All patients were willing to participate and consented to their inclusion with formal written consent when recruited.

We performed a longitudinal prospective evaluation of our patients.

Inclusion criteria were: age $>18 \mathrm{y}$, moderate OSAS $(15<\mathrm{AHI}<30)$ and nasal obstructive symptoms that compromised QOL. Exclusion criteria were: previous upper airways surgery and weight loss $>10 \%$ body weight between surgery and follow-up, since it has been demonstrated that weight loss inferior to $10 \%$ of total body weight has no polysomnographic effects on moderate OSAS patients ${ }^{13}$.

All patients underwent pre-operative otolaryngological evaluation including fibre optic nasopharyngoscopy with Muller's maneuver, home respiratory polygraph (Somntè Recording Unit ${ }^{\oplus}$, Somntè Compumedics, Australia). Subjective evaluation was obtained using the Italian translation of strongly validated questionnaires, namely the Sino-Nasal Outcome Test (SNOT-20) ${ }^{14}{ }^{15}$ (Fig. 2) and Epworth Sleepiness Scale (ESS) ${ }^{7}$ (Fig. 1).
During the same surgical session, all patients underwent DISE with the presence of an anaesthesiologist, neuroelectrophysiology technician and ENT specialist. Patients, already prepared for polygraphic intraoperative recording, received drug sedation. For drug sedation, we used an increasing dose of propofol $(3 \mathrm{mg} / \mathrm{kg} / \mathrm{h})$ until continuous BiSpectral Index (BIS) monitoring by Aspect A-2000 BIS monitor $^{\oplus}$ (Apect Medical Systems, Natick, MA), was between 45-65. During snoring, we introduced flexible nasopharyngoscope trough the nasal cavity evaluating the pattern and degree of obstruction (nasopharynx, oropharynx, hypopharynx and larynx) and continuously monitored sleep with a polygraph (Somntè Compumedics System ${ }^{\circledR}$, Somntè Compumedics, Australia). We also performed a bimanual pull-up mandibular advancement manoeuvre, advancing from 4 to $5 \mathrm{~mm}^{16}{ }^{17}$, evaluating masseter muscle activation ${ }^{18}$ and visualising the effect on airway obstruction.

After these procedures, starting ventilation using a cuffed laryngeal mask, we performed TD with a quantic molecular resonance scalpel (Teleamedical ENT Quantum Bipolar Scalpel).

Patients were re-evaluated at six months after surgical 


\begin{tabular}{|c|c|c|c|c|c|c|c|}
\hline \multicolumn{8}{|c|}{$\begin{array}{l}\text { Belopv you will find a list of symptoms and social/emotional consequences of your rhinosinusitis. We would like to know } \\
\text { more about these problems and would appreciate your answering the following questions to the best of your ability. There are } \\
\text { no right or wrong answers, and only you can provide us with this information. Please rate your problems as they have been } \\
\text { over the past two weeks. Thank you for your participation. Do not hesitate to ask for assistance if necessary. }\end{array}$} \\
\hline $\begin{array}{l}\text { 1. Considering how severe the problem is when you } \\
\text { experience it and how frequently it happens, } \\
\text { please rate each item below on how "bad" it is by } \\
\text { circling the number that corresponds with how } \\
\text { you feel using this scale: } \rightarrow\end{array}$ & 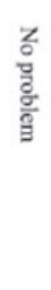 & 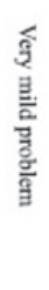 & 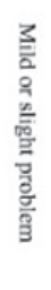 & 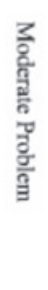 & 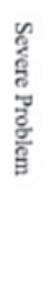 & 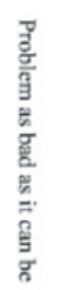 & 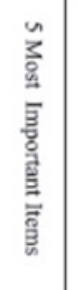 \\
\hline 1. Need to blow nose & 0 & 1 & 2 & 3 & 4 & 5 & 0 \\
\hline 2. Sneezing & 0 & 1 & 2 & 3 & 4 & 5 & 0 \\
\hline 3. Runny nose & 0 & 1 & 2 & 3 & 4 & 5 & 0 \\
\hline 4. Cough & 0 & 1 & 2 & 3 & 4 & 5 & o \\
\hline 5. Post-nasal discharge & 0 & 1 & 2 & 3 & 4 & 5 & 0 \\
\hline 6. Thick nasal discharge & 0 & 1 & 2 & 3 & 4 & 5 & o \\
\hline 7. Ear fullness & 0 & 1 & 2 & 3 & 4 & 5 & o \\
\hline 8. Dizziness & 0 & 1 & 2 & 3 & 4 & 5 & 0 \\
\hline 9. Ear pain & 0 & 1 & 2 & 3 & 4 & 5 & o \\
\hline 10. Facial pain/pressure & 0 & 1 & 2 & 3 & 4 & 5 & 0 \\
\hline 11. Difficulty falling asleep & 0 & 1 & 2 & 3 & 4 & 5 & 0 \\
\hline 12. Wake up at night & 0 & 1 & 2 & 3 & 4 & 5 & o \\
\hline 13. Lack of a good night's sleep & 0 & 1 & 2 & 3 & 4 & 5 & 0 \\
\hline 14. Wake up tired & 0 & 1 & 2 & 3 & 4 & 5 & 0 \\
\hline 15. Fatigue & 0 & 1 & 2 & 3 & 4 & 5 & 0 \\
\hline 16. Reduced productivity & 0 & 1 & 2 & 3 & 4 & 5 & ० \\
\hline 17. Reduced concentration & 0 & 1 & 2 & 3 & 4 & 5 & o \\
\hline 18. Frustrated/restless/irritable & 0 & 1 & 2 & 3 & 4 & 5 & 0 \\
\hline 19. Sad & 0 & 1 & 2 & 3 & 4 & 5 & 0 \\
\hline 20. Embarrassed & 0 & 1 & 2 & 3 & 4 & 5 & 0 \\
\hline 2. Please mark the most important items affecting you & health & 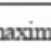 & 1 of 5 & $\mathrm{~ms}$ & & & 8 \\
\hline
\end{tabular}

Fig. 2. SNOT-20 questionnaire (Mozzanica F, et al., $2017^{15}$ ).

procedures and the SNOT-20 and ESS questionnaires were administered.

Data obtained by SNOT and ESS are expressed as mean \pm standard deviation (SD). We compared the means of ESS results, total SNOT score and sums of questions 1-10 and 11-20 as representative of nasal symptoms and QOL, respectively.

Statistical analysis of data was performed using Microsoft EXCEL and IBM SPSS 24 software packages, comparing the means with T-test for paired samples. Data were considered positive if there was a decrease in SNOT and
ESS scores after treatment. Differences were considered statistically significant if the $\mathrm{p}$ value was less than 0.05 .

\section{Results}

Table I shows the results of ESS, total SNOT scores and partial SNOT scores for each patient.

We observed a significant improvement $(\mathrm{p}<0.05)$ in both the ESS medium index $(6.03 \pm 2.75$ vs $4.16 \pm 4.63$; Fig. 3) and in the total SNOT score $(22.53 \pm 12.16$ vs $13.23 \pm 10.82$; Fig. 4). A significant difference $(\mathrm{p}<0.05)$ 
Table I. Per patient values, pre- and post-operative for ESS, the total Snot score and the partial scores for question 1-10 and 11-20. At bottom provided means and standard deviations.

\begin{tabular}{|c|c|c|c|c|c|c|c|c|}
\hline ID & EpworthPre & EpworthPost & TotalSnotPre & TotalSnotPost & 1-10 SnotPre & 1-10 SnotPost & 11-20 SnotPre & 11-20 SnotPost \\
\hline 1 & 8.00 & 4.00 & 54.00 & 11.00 & 16.00 & 7.00 & 38.00 & 4.00 \\
\hline 2 & 4.00 & 0.00 & 32.00 & 0.00 & 18.00 & 0.00 & 14.00 & 0.00 \\
\hline 3 & 4.00 & 4.00 & 17.00 & 15.00 & 11.00 & 14.00 & 6.00 & 1.00 \\
\hline 4 & 6.00 & 4.00 & 20.00 & 18.00 & 15.00 & 7.00 & 5.00 & 11.00 \\
\hline 5 & 5.00 & 3.00 & 20.00 & 11.00 & 12.00 & 9.00 & 8.00 & 2.00 \\
\hline 6 & 6.00 & 19.00 & 19.00 & 37.00 & 7.00 & 9.00 & 12.00 & 28.00 \\
\hline 7 & 3.00 & 0.00 & 21.00 & 10.00 & 10.00 & 10.00 & 11.00 & 0.00 \\
\hline 8 & 7.00 & 3.00 & 17.00 & 9.00 & 9.00 & 9.00 & 8.00 & 0.00 \\
\hline 9 & 3.00 & 0.00 & 4.00 & 0.00 & 2.00 & 0.00 & 2.00 & 0.00 \\
\hline 10 & 6.00 & 6.00 & 46.00 & 29.00 & 8.00 & 5.00 & 38.00 & 24.00 \\
\hline 11 & 6.00 & 8.00 & 17.00 & 19.00 & 7.00 & 9.00 & 10.00 & 10.00 \\
\hline 12 & 9.00 & 8.00 & 18.00 & 23.00 & 1.00 & 2.00 & 17.00 & 21.00 \\
\hline 13 & 13.00 & 3.00 & 26.00 & 2.00 & 5.00 & 2.00 & 21.00 & 0.00 \\
\hline 14 & 10.00 & 4.00 & 23.00 & 25.00 & 3.00 & 4.00 & 20.00 & 21.00 \\
\hline 15 & 12.00 & 2.00 & 44.00 & 1.00 & 20.00 & 1.00 & 24.00 & 0.00 \\
\hline 16 & 3.00 & 3.00 & 5.00 & 9.00 & 2.00 & 7.00 & 3.00 & 2.00 \\
\hline 17 & 8.00 & 1.00 & 15.00 & 5.00 & 11.00 & 5.00 & 4.00 & 0.00 \\
\hline 18 & 3.00 & 2.00 & 15.00 & 2.00 & 4.00 & 2.00 & 11.00 & 0,00 \\
\hline 19 & 4.00 & 4.00 & 16.00 & 2.00 & 4.00 & 2.00 & 12.00 & 0,00 \\
\hline 20 & 8.00 & 8.00 & 35.00 & 19.00 & 11.00 & 8.00 & 24.00 & 11,00 \\
\hline 21 & 5.00 & 0.00 & 31.00 & 0.00 & 17.00 & 0.00 & 13.00 & 0,00 \\
\hline 22 & 3.00 & 3.00 & 18.00 & 16.00 & 11.00 & 15.00 & 7.00 & 2,00 \\
\hline 23 & 5.00 & 3.00 & 19.00 & 17.00 & 16.00 & 8.00 & 6.00 & 12,00 \\
\hline 24 & 5.00 & 3.00 & 20.00 & 11.00 & 10.00 & 7.00 & 6.00 & 1,00 \\
\hline 25 & 6.00 & 4.00 & 19.00 & 37.00 & 7.00 & 9.00 & 12.00 & 28,00 \\
\hline 26 & 3.00 & 0.00 & 21.00 & 10.00 & 10.00 & 10.00 & 11.00 & 0,00 \\
\hline 27 & 7.00 & 3.00 & 17.00 & 9.00 & 9.00 & 9.00 & 8.00 & 0,00 \\
\hline 28 & 3.00 & 0.00 & 4.00 & 0.00 & 2.00 & 0.00 & 2.00 & 0,00 \\
\hline 29 & 10.00 & 4.00 & 46.00 & 29.00 & 8.00 & 5.00 & 38.00 & 24,00 \\
\hline 30 & 6.00 & 4.00 & 17.00 & 19.00 & 7.00 & 9.00 & 10.00 & 10,00 \\
\hline \multicolumn{9}{|c|}{ Means and standard deviation } \\
\hline & $6.03 \pm 2.75$ & $4.17 \pm 4.63$ & $22.53 \pm 12.16$ & $13.16 \pm 10.81$ & $9.10 \pm 5.11$ & $6.13 \pm 4.11$ & $13.37 \pm 10.20$ & $7,07 \pm 9,68$ \\
\hline
\end{tabular}

was also identified for partial SNOT questions 1-11 $(9.1 \pm 5.11$ vs $6.13 \pm 4.12)$ and $11-20(13.36 \pm 10.20$ vs $7.13 \pm 9.644$; Fig. 4)

No patient had any complications related to DISE, and only two patients $(6.67 \%)$ presented intra-operative epistaxis that required nasal swab during TD.

\section{Discussion}

The results of the present study confirm that TD alone can improve sleepiness, QOL and nasal symptoms. We used well-known and validated questionnaires, which implies subjective assessment by patients. However, subjective data can be considered reliable, and the clinical correlation between SNOT score, ESS index and OSAS has already been described 1920 .

Sleepiness score can be considered the better index of OSAS outcomes. In the present study, it was reduced by $68.9 \%$, with an absolute score of 1.87 points. The importance of TD in the amelioration of disability OSAS-related is also evident. In agreement with literature data, we can confirm that resolution of nasal obstruction generally alleviates daytime sleepiness in OSAS patients ${ }^{20}{ }^{21}$, even if it has little effect on $\mathrm{AHI}{ }^{22}$. 


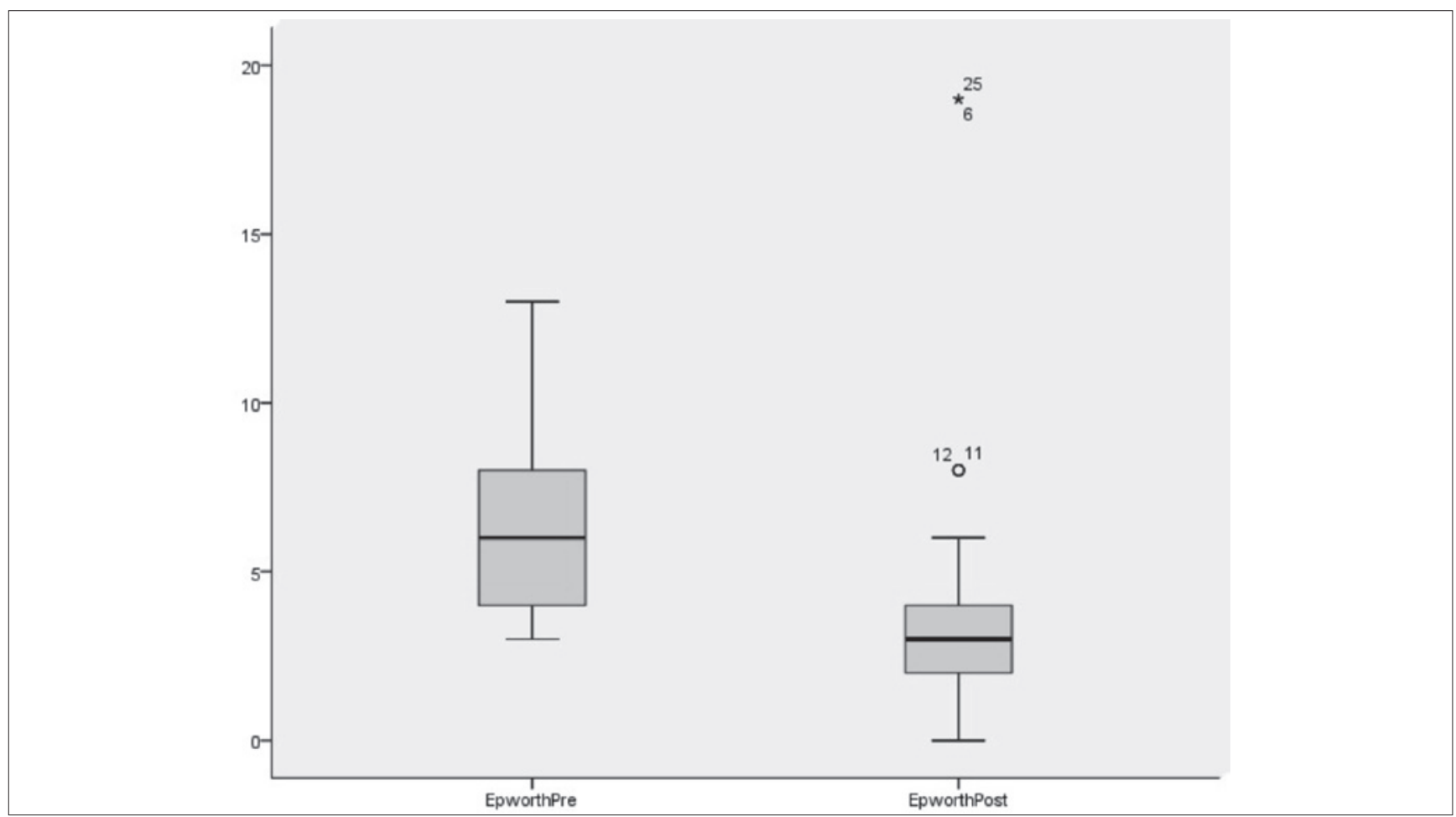

Fig. 3. Epworth score distribution at baseline and after six months after turbinate decongestion. The box plots show the median and inter-quartile range and the error bars show the $5^{\text {th }}$ and $95^{\text {th }}$ percentiles.

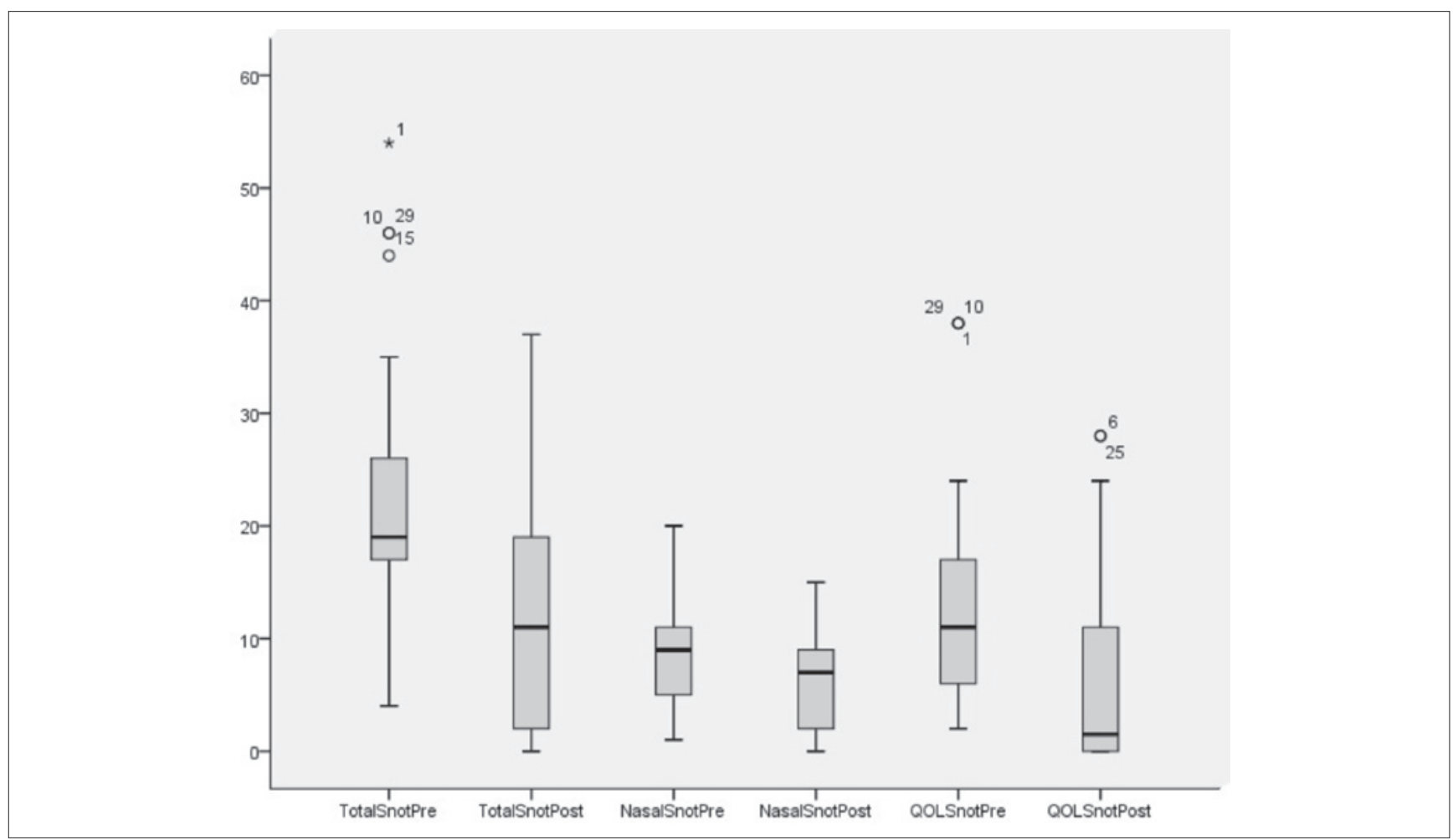

Fig. 4. SNOT-20 score distribution at baseline and after six months from turbinates' decongestion. From left to right: Total Score, Question 1-10 Score, Questions 11-20 Score. The box plots show the median and inter-quartile range and the error bars show the $5^{\text {th }}$ and $95^{\text {th }}$ percentiles. 
We showed a significant modification of total SNOT score, which was reduced by 9.3 (58.7\%). Moreover, evaluation of the partial SNOT score also showed a significant improvement. In particular, questions 11-20 investigate nasal obstruction related symptoms such as fatigue, sleepiness, lack of concentration and emotional burden; we highlight that the score decreased by $6.2(53.3 \%)$. Questions 1-10 examine nasal symptoms, and showed were reduced by $3(67.3 \%)$. This high percentage confirms that nasal symptoms ameliorate after TD, as stated by the American Academy of Otolaryngology-Head And Neck Surgery ${ }^{23}$. Moreover, the QOL can be considered to be a very significant aspect in management of OSAS patients, and comprises symptoms such as daytime sleepiness, fatigue, reduction in concentration and productivity, irritability and snoring that could cast away sleeping partners. Excessive daytime sleepiness is one of the principal symptoms in patients with OSAS causing reduced productivity, accidents, and errors in professional life are a serious social concern; worsening QOL thus deserves attention by the physician. Our results further confirm the efficacy of TD in improving the QOL. Assuming that nasal obstruction could be due to turbinate hypertrophy, septal deviation, nasal polyps, rhinosinusitis, neoplasm of nasal cavity and nasal valve collapse, we can argue that it is responsible not only for nasal symptoms, but also for extra nasal symptoms such as fatigue, sleep disturbances, headache and daytime sleepiness, and for this reason it causes a decline in $\mathrm{QOL}^{923}$. In OSAS patients, nasal resistance is frequently high and varies with body position: it increases in the supine position, compared with the upright position, and is due to an increase in nasal blood flow and reduction of the retropalatal space ${ }^{11}$.

Finally, considering the aetiology of chronic nasal obstruction, it cannot be resolved by medical therapy alone, often requiring surgical treatment.

We conclude that given the relative safety ${ }^{24}$ of turbinate decongestion, its acknowledged good cost/efficacy ratio in supporting CPAP therapy and the beneficial effects on QOL and sleepiness we found, TD can be considered too important in the management of all patients with OSAS and nasal obstruction.

Another final matter that supports our recommendation is the good cost/efficacy ratio of TD and the short timespan (5 years) for good effects, compared to septal correction that performs the best results in 10-15 years, and improvement of CPAP compliance ${ }^{10}$.

\section{Conclusions}

Our results suggest that in the absence of a National Health System recognition for DISE, the association of this procedure with TD can be useful not only for diagnostic purposes, but also for suitable management of OSAS, improving the CPAP compliance and adherence, reducing the sleepiness, ameliorating the nasal symptoms, and therefore QOL.

Moreover, at the cost of only one day surgery and one anaesthesiological procedure, we associated an endoscopic diagnostic procedure with surgical treatment.

Finally, teams managing patients with snoring and sleep apnoea should continue their investigations in order to determine whether DISE is fundamental for guiding good medical practice, and to render DISE a more widespread procedure that is useful in OSAS beyond economic considerations alone.

\section{References}

1 Croft CB, Pringle M. Sleep nasendoscopy: a technique of assessment in snoring and obstructive sleep apnoea. Clin Otolaryngol Allied Sci 1991;16:504-9.

2 Blumen M, Bequignon E, Chabolle F. Drug-induced sleep endoscopy: a new gold standard for evaluating OSAS? Part I: technique. Eur Ann Otorhinolaryngol Head Neck Dis 2017;134:101-7.

3 Blumen M, Bequignon E, Chabolle F. Drug-induced sleep endoscopy: a new gold standard for evaluating OSAS? Part II: results. Eur Ann Otorhinolaryngol Head Neck Dis 2017;134:109-15.

4 De Corso E, Fiorita A, Rizzotto G, et al. The role of druginduced sleep endoscopy in the diagnosis and management of obstructive sleep apnoea syndrome: our personal experience. Acta Otorhinolaryngol Ital 2013;33:405-13.

5 Wu J, Zhao G, Li Y, et al. Apnea-hypopnea index decreased significantly after nasal surgery for obstructive sleep apnea: a meta-analysis. Medicine (Baltimore) 2017;96:e6008.

6 Camacho M, Riaz M, Capasso R, et al. The effect of nasal surgery on continuous positive airway pressure device use and therapeutic treatment pressures: a systematic review and meta-analysis. Sleep 2015;38:279-86.

7 Vignatelli L, Plazzi G, Barbato A, et al.; GINSEN (Gruppo Italiano Narcolessia Studio Epidemiologico Nazionale). Italian version of the Epworth sleepiness scale: external validity. Neurol Sci 2003;23:295-300.

8 Powell NB, Zonato AI, Weaver E, et al. Radiofrequency treatment of turbinate hypertrophy in subjects using continuous positive airway pressure: a randomized, boubleblind, placebo-controlled clinical pilot trial. Laryngoscope 2001;111:1783-90.

9 Ishii L, Roxbury C, Godoy A, et al. Does nasal surgery improve OSA in patients with nasal obstruction and OSA? A meta-analysis. Otolaryngol Head Neck Surg 2015;153:326-33.

10 Kempfle JS, BuSaba NY, Dobrowski JM, et al. A cost-effectiveness analysis of nasal surgery to increase continuous 
positive airway pressure adherence in sleep apnea patients with nasal obstruction. Laryngoscope 2017;127:977-83.

11 Badr MS. Pathophysiology of upper airway obstruction during sleep. Clin Chest Med 1998;19:21-32.

12 Georgalas $\mathrm{C}$. The role of the nose in snoring and obstructive sleep apnoea: an update. Eur Arch Otorhinolaryngol 2011;268:1365-73.

13 Papandreou C, Hatzis CM, Fragkiadakis GA. Effects of different weight loss percentages on moderate to severe obstructive sleep apnoea syndrome. Chron Respir Dis 2015;12:276-8.

14 Pynnonen MA, Kim HM, Terrell JE. Validation of the sinonasal outcome Test 20 (SNOT-20) domains in nonsurgical patients. Am J Rhinol Allergy 2009;23:40-5.

15 Mozzanica F, Preti A, Gera R, et al. Cross-cultural adaptation and validation of the SNOT-22 into Italian. Eur Arch Otorhinolaryngol 2017;274:887-95.

16 De Corso E, Bastanza G, Della Marca G, et al. Drug-induced sleep endoscopy as a selection tool for mandibular advancement therapy by oral device in patients with mild to moderate obstructive sleep apnoea. Acta Otorhinolaryngol Ital 2015;35:426-32.

17 Scarano E, Della Marca G, De Corso E, et al. Hyoid myotomy without suspension: a surgical approach to obstructive sleep apnoea syndrome. Acta Otorhinolaryngol Ital 2014;34:362-7.

18 Marchese MR, Scarano E, Rizzotto G, et al. The role of mas- seter muscle EMG during DISE to predict the effectiveness of MAD: preliminary results. Acta Otorhinolaryngol Ital 2016;36:486-9.

19 Chiu HY, Chen PY, Chuang LP, et al. Diagnostic accuracy of the Berlin questionnaire, STOP-BANG, STOP, and Epworth sleepiness scale in detecting obstructive sleep apnea: a bivariate meta-analysis. Sleep Med Rev 2017;36:57-70.

20 Farhood Z, Schlosser RJ, Pearse ME, et al. Twenty-two item sino-nasal outcome test in a control population: a cross-sectional study and systematic review. Int Forum Allergy Rhinol 2016;6:271-7.

21 Udaka T, Suzuki H, Kitamura T, et al. Relationships among nasal obstruction, daytime sleepiness, and quality of life. Laryngoscope 2006;116:2129-32.

22 Li HY, Lin Y, Chen NH, et al. Improvement in quality of life after nasal surgery alone for patients with obstructive sleep apnea and nasal obstruction. Arch Otolaryngol Head Neck Surg 2008;134:429-33.

23 Han JK, Stringer SP, Rosenfeld RM, et al. Clinical consensus statement: septoplasty with or without inferior turbinate reduction. Otolaryngol Head Neck Surg 2015;153:708-20.

24 Kim ST, Choi JH, Jeon HG, et al. Polysomnographic effects of nasal surgery for snoring and obstructive sleep apnea. Acta Otolaryngol 2004;124:297-300.

Received: September 5, 2017- Accepted: January 24, 2018

Address for correspondence: Emanuele Scarano, Istituto di Clinica ORL, largo A. Gemelli 8, 00168 Roma, Italy. Tel. +39 06 30154439. Fax +3906 3051194. E-mail: escarano@tim.it rodolfomastrapasqua@gmail.com 